\title{
Laparoscopic colectomy for primary colonic lymphoma
}

\author{
D. Martínez-Ramos, J. Gibert-Gerez, J. M. Miralles-Tena, M. Martínez-Banaclocha ${ }^{1}$ J. Escrig-Sos \\ and J. L. Salvador-Sanchís
}

Departments of General and Digestive Surgery, and 'Pathology. General Hospital. Castellón, Spain

\begin{abstract}
Primary colorectal lymphoma is an infrequent disease of unknown origin and with a growing incidence. Differentiation between primary lymphoma and secondary colorectal involvement is of great therapeutic and prognostic importance. The diagnosis must always be based on histological findings. Different forms of presentation have been described, though all are nonspecific. While full agreement on the best management approach for colorectal lymphoma is lacking, surgical resection is usually the treatment of choice. The role of chemotherapy has not been defined. This study reports on a case of primary lymphoma in the cecum, with clinical manifestations in the form of meteorism and early satiety. The diagnosis was established by colonoscopy and biopsy. The absence of lymph-node involvement, tumor size, existing cardiopulmonary risk factors, and the fact that a full resection of the malignancy proved possible, with tumor-free resection margins, led us to exclude adjuvant chemotherapy. After one year of follow-up the patient remains disease-free.
\end{abstract}

Key words: Laparoscopic surgery. Intestinal lymphoma. Colorectal lymphoma. Non-Hodgkin lymphoma.

Martínez-Ramos D, Gibert-Gerez J, Manuel Miralles-Tena JM, Martínez-Banaclocha M, Escrig-Sos J, Salvador-Sanchís JL. Laparoscopic colectomy for primary colonic lymphoma. Rev Esp Enferm Dig 2005; 97: 744-749.

\section{INTRODUCTION}

Since Billroth first described a gastrointestinal lymphoma in 1871, numerous lymphoid tumors have been reported in virtually all parts of the digestive tract. Lym-

Recibido: 25-04-05.

Aceptado: 26-04-05.

Correspondencia: David Martínez-Ramos. Servicio de Cirugía General y Digestiva. Hospital General de Castellón. Avda. Benicàssim, s/n, 12004 Castellón.e-mail: davidmartinez@ comcas.es phomas may appear in the colon as primary malignancies or as a manifestation of systemic disease. Differentiation between primary colonic lymphoma (PCL) and secondary colorectal involvement is of great therapeutic and prognostic importance.

Primary colonic lymphoma is very uncommon, and mainly manifests in the sixth decade of life. The underlying etiology remains unclear. However, the incidence of this tumor is increasing, and its presentations are varied. Knowledge of the forms of presentation is therefore important in order to suspect the disease and reach an early diagnosis -this being one of the main aspects conditioning patient prognosis.

The present study describes a case of cecal lymphoma without involvement of any other organ, in which the initial manifestation was meteorism. Surgery was the treatment of choice.

\section{CASE REPORT}

A 78-year-old male with a history of arterial hypertension and double aortic valve lesion presented with meteorism and early postprandial fullness. On different occasions he had experienced abdominal distension with expulsion of gases. The physical examination was normal, with no palpable adenopathies, masses or enlarged organs, and with a good nutritional condition. A complete blood count and biochemical panel was normal. An opaque enema showed a contrast filling defect in the cecum. Colonoscopy confirmed the presence of an extensive mass in the cecal region, and multiple biopsies were collected. Histology reported a large B cell lymphoma with a high proliferation index. Neck, chest and abdominal computed tomography scans and an ultrasonographic study of disease spread revealed no additional lesions. A bone marrow study proved normal. Viral serology (including HIV) was negative. 
Surgery was decided in the form of laparoscopic rightside colectomy with intracorporeal vascular control and mobilization. An extended McBurney incision was made, exteriorizing the right colon and performing ileo-colonic resection followed by side-to-side anastomosis with a mechanical stapler. A liver biopsy was obtained during the operation.

The surgical piece contained a colon-cecal segment $25 \mathrm{~cm}$ in length, and a 6-cm piece of terminal ileum. The tumor consisted of a diffuse circumferential thickening of the cecal wall, to a thickness of $1.5 \mathrm{~cm}$, with infiltration of the fatty tissue. A histological and immunohistochemical study confirmed the presence of a large B cell lymphoma, with a high proliferative index (Fig. 1). Surgical resection margins, lymph nodes, epiploon and liver biopsy were free of disease.

One year later the patient remains asymptomatic, with no evidence of relapse.

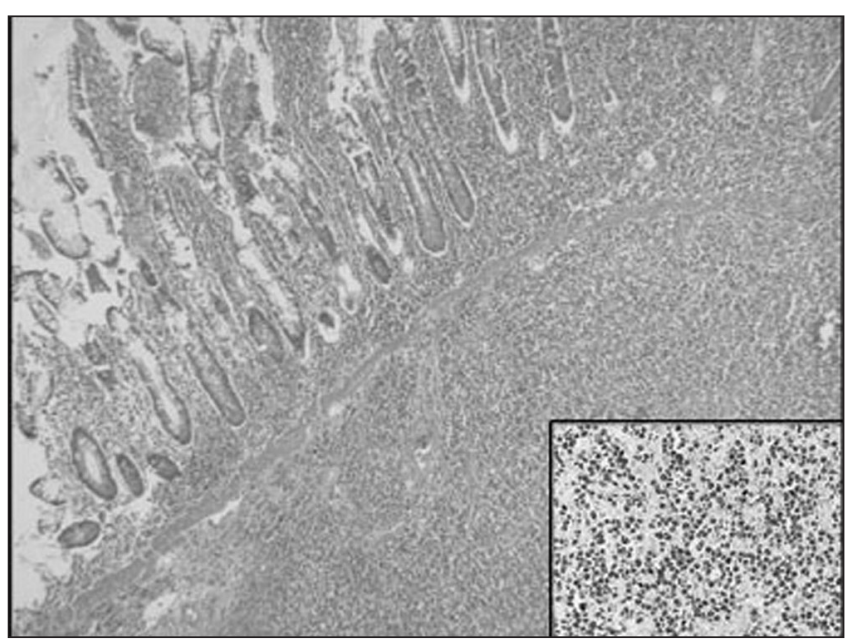

Fig. 1.- Histological section of the colon wall showing infiltration by a diffuse large B cell lymphoma (hematoxylin-eosin, 40x). The neoplasm affects the mucosa, submucosa and muscularis propria, with a high cell proliferation index. Right lower inset: Ki67 via immunohistochemistry, 200x.

Sección histológica de la pared del colon infiltrada por un linfoma $B$ difuso de célula grande (HE, 40X). La neoplasia afecta mucosa, submucosa y muscular propia, mostrando un alto índice de proliferación celular. Margen inferior derecho: Ki67 por inmunohistoquímica, 200X.

\section{DISCUSSION}

The gastrointestinal tract (particularly the small intestine and stomach) is the most common location of extralymph-node non-Hodgkin lymphomas. The colon is affected in only $5-20 \%$ of cases. In this context, primary colonic lymphoma (PCL) accounts for $0.2-0.5 \%$ of all neoplasms in this location, with a prevalence of 0.02 per 100,000 inhabitants (1-6). In the colon, the cecum is the most frequently affected segment, followed by the rectum. This is probably explained by the more abundant lymphatic tissue found in these regions. In 5\% of cases synchronic lesions and multiple lymphomatous polyps are also observed (1-8).

According to most publications, PCL has a peak incidence in patients between 50-70 years of age, though cases have been reported in patients aged 3-86 years. The male/female ratio is $2 / 1$ or higher $(1,2,4)$, and the disease usually comprises non-Hodgkin B cell lymphoma in the mucosa-associated lymphatic tissue (MALT) $(2,3,8)$. T cell intestinal lymphomas are even less frequent, though the difference between both tumor types is less manifest in Asia $(6,7)$. Likewise, there have been isolated reports of $T$ cell lymphoma associated with celiac disease, and presenting a poorer prognosis $(1,9)$. According to Romaguera et al. (10), mantle- and marginal zone-cell lymphomas of the colon are probably more common than previously believed. The histological grade of PCL according to the Working Formulation varies from low to moderate or high, with a predominance of one form or the other according to the series published in the literature $(3,11,12)$.

The cause underlying primary colonic lymphoma is unknown, though different factors have been postulated, including immune suppression (HIV infection, corticotherapy, treatment of transplant patients, etc.) or inflammatory bowel disease. According to some authors, the relation of PCL to AIDS may account for the increased incidence of the former in recent years (1-3). Similarly to stomach level, Matsumoto et al. have suggested that PCL may be related to $H$. pylori infection $(8,13)$.

The most common clinical presentation is in the form of nonspecific, chronic and poorly localized abdominal pain, with a palpable abdominal mass and weight loss. Other presentations include anemic syndrome, chronic bleeding, rectal bleeding, acute abdomen secondary to perforation, intussusception, or inflammatory bowel disease-like illness $(2-4,11,14)$. Although changes in bowel habit have been reported in some cases, a search of the literature has revealed no cases of intermittent meteorism or early satiety as initial manifestations.

Imaging techniques used in the diagnosis of PCL include computer axial tomography (essential for tumor staging) and double-contrast barium enema to detect minor mucosal defects, complications such as fistulas or perforations, and to precisely identify the location of the lesion. Nevertheless, PCL may simulate any form of radiological presentation (15).

In all cases a definitive diagnosis is established histologically by studying biopsy samples obtained during colonoscopy (the most common situation), or by the histopathological evaluation of the surgical resection piece. Wang et al. described three types of endoscopic presentation: mucosal (erosive or ulcerated), polypoid and massive (7). Subsequently, Myung et al. reported three primary presentations: fungous, ulcerative, and infiltrative -with intermediate ulcero-fungous and ulceroinfiltrative variants (6). 
In order to establish a correct diagnosis, it is essential to differentiate PCL from colonic involvement of systemic lymphoma, since the corresponding prognoses and treatments are very different. Accordingly, in 1961, Dawson established the criteria shown in table I (16) that explain why, in addition to a thorough physical examination to rule out peripheral adenopathies, it is essential that a chest computed tomography be performed, as well as an assessment of peripheral blood and bone marrow.

\section{Table I. Dawson criteria for the diagnosis of primary} digestive tube lymphoma

-Gastrointestinal tumor histologically confirmed to be a lymphoma -Absence of hepatomegaly and/or splenomegaly

-Absence of peripheral adenopathies

-Absence of evidence of chest lymphoma via computed tomography or X-rays

-Normal blood and bone marrow biopsy findings

The Ann Arbor staging system, initially proposed for Hodgkin lymphomas, has also been adopted as a model for non-Hodgkin lymphomas. Despite limitations, this system has received international acceptance and defines primary management guidelines. Musshoff and SchmidtVollmer (17) proposed a modification of this classification specifically adapted to gastrointestinal lymphomas, with the advantage of dividing stage II into stages II1 and II2, according to whether the patient has either regional or distant lymph-node involvement (Table II).

Table II. Modified staging of gastrointestinal non-Hodgkin lymphoma

\begin{tabular}{ll}
\hline Stage I & Tumor confined to the gastrointestinal tract (IE) \\
Stage II & $\begin{array}{l}\text { Tumor with regional lymph node involvement (IIE 1) } \\
\text { or with lymph node involvement beyond regional } \\
\text { lymph nodes (IIE 2) }\end{array}$ \\
Stage III & $\begin{array}{l}\text { Tumor with involvement of other abdominal (liver, } \\
\text { spleen) or extra-abdominal organs (thorax, bone } \\
\text { marrow) }\end{array}$ \\
\hline
\end{tabular}

Most authors agree that the initial treatment of PCL should include surgical resection, since this affords prognostic information, avoids complications (bleeding, occlusion, etc.), and allows healing of the disease in some cases. Since the cecum is most commonly affected, a right-side colectomy is usually indicated $(1-4,8,11)$. It is advisable that a resection of regional lymph nodes be included, since these are usually found to be affected in the histological study, and a liver biopsy is mandatory. Laparoscopic resection of colon tumors has been shown to meet standard oncological criteria, and further offers important advantages in terms of both morbidity and mortality (18), particularly in elderly patients or individuals with relevant concomitant diseases (as in our case) (19).

An extensive review of the literature has revealed no agreement among authors as to the type of adjuvant therapy indicated in these patients. In effect, some authors reserve chemotherapy for disseminated or advanced disease $(5,8)$, while others provide such treatment in all cases $(1,3,4,14)$. Some investigators even consider that there is no difference between administering chemotherapy or not $(6,11,12)$. However, although no benefits in terms of prolonged patient survival have been demonstrated, the tendency in recent years is to administer postoperative chemotherapy despite the fact that the number of patients in all published series is very limited, and no comparative studies have been made among the different management options -thus precluding the drawing of firm conclusions. We therefore consider coordination among the different specialists involved in the management of such patients to be is essential in order to address each case according to the individual patient characteristics. In our case, the absence of lymph node involvement, the size of the tumor, the existing cardiopulmonary risk factors, and the fact that full resection of the malignancy proved possible, with tumor-free resection margins, led us to exclude adjuvant chemotherapy.

In the more recent series, radiotherapy is limited to the treatment of rectal lymphomas (4). In this context, Matsumoto et al. have reported the regression of a rectal lymphoma following endoscopic resection and eradication treatment for H. pylori (13).

Most authors agree that in advanced stages of the disease (lymph node involvement), tumor size and grade, incomplete tumor resection, and acute abdomen secondary to perforation are all indicative of poor prognosis $(1,2,5)$ However, Fan et al. (11) consider that only histological grade is of prognostic importance. In any case, the limited sample size in all these series may be insufficient to allow firm conclusions to be drawn.

In conclusion, primary colonic lymphoma is infrequent, and, therefore, little known -with no standardized treatment or definition of the natural history of the disease. Laparoscopic resection of the tumor affords oncological control similar to that obtained with conventional surgery, though with much less morbidity-mortality, and with significant postoperative advantages.

\section{REFERENCES}

1. Villanueva-Sáenz E, Álvarez-Tostado JF, Martínez Hernández-Magro P, Valdés-Ovalle M, Pena Ruiz-Esparza JP. Linfoma primario de colon. Rev Gastroenterol Mex 2002; 67: 28-33.

2. Doolabh N, Anthony T, Simmang C, Bieligk S, Lee E, Huber P, et al. Primary colonic lymphoma. J Surg Oncol 2000; 74: 257-62.

3. Zighelboim J, Larson MV. Primary colonic lymphoma. Clinical presentation, histopathologic features, and outcome with combination 
chemotherapy. J Clin Gastroenterol 1994; 18 (4): 291-7.

4. Aragón Sánchez FJ, García Molina FJ, Rodríguez Fernández A, de Dios Franco Osorio J, Ortegón Castellano B, et al. Linfoma colorrectal primario. Rev Esp Enferm Dig 1997; 89 (12): 903-18.

5. Matkovic S, Jelic S, Manojlovic N, Milanovic N. Non-Hodgkin's lymphomas with primary localization in large bowel and rectum. Med Sci Monit 2000; 6 (1): 68-74.

6. Myung SJ, Joo KR, Yang SK, Jung HY, Chang HS, Lee HJ, et al. Clinicopathologic features of ileocolonic malignant lymphoma: analysis according to colonoscopic classification. Gastrointestinal Endoscopy 2003; 57 (3): 343-7.

7. Wang MH, Wong JM, Lien HC, Lin CW, Wang CY. Colonoscopic manifestations of primary colorectal lymphoma. Endoscopy 2001; 33 (7): 605-9.

8. Matsumoto T, Shimizu M, Iida M, Amano K, Nakamura S, Fujishima M. Primary low-grade, B-cell, mucosa-associated lymphoid tissue lymphoma of the colorectum: clinical and colonoscopic features in six cases. Gastrointesteinal Endoscopy 1998; 48 (5): 501-8.

9. Koo V, Amstrong A, Harvey C. Coeliac disease presenting with colonic lymphoma. The Ulster Medical Journal 2002; 71 (2): 136-8.

10. Romaguera J, Hagemeister FB. Lymphoma of the colon. Curr Opin Gastroenterol 2005; 21 (1): 80-4.

11. Fan CW, Changchien CR, Wang JY, Chen JS, Hsu KC, Tang R, et al.
Primary colorectal lymphoma. Dis Colon Rectum 2000; 43: 1277-82.

12. Cho MJ, Ha CS, Allen PK, Fuller LM, Cabanillas F, Cox JD. Primary non-Hodgkin lymphoma of the large bowel. Radiology 1997; 205 (2): 535-9.

13. Matsumoto T, Iida M, Shimizu M. Regression of mucosa-associated lymphoid-tissue lymphoma of the rectum after eradication of Helicobacter pylori. The Lancet 1997; 350: 115-6.

14. Luo JC, Hwang SJ, Li CP, Liu JH, Chen PM, Liu SM, et al. Primary low grade B-cell lymphoma of colon mimicking inflammatory bowel disease: a case report. Zhonghua Yi Xue Za Zhi 1997; 59 (6): 367-71. (Abstract)

15. Kropivnik M, et al. Primary non-Hodgkin lymphoma of the cecum: A case report. Radiol Oncol 2002; 36 (1): 1-4.

16. Dawson IMP, Cornes JS, Morson BC. Primary malignant lymphoid tumors of the intestinal tract. Report of 37 cases with a study of factors influencing prognosis. Br J Surg 1961; 49: 80-9.

17. Musshof K. Klinische stadieneinteilung der Nicht-Hodgkin-Lymphome. Strehlentherapie 1977; 153: 218-21

18. Senagore AJ, Brady KM, Fazio VW. Standardiezed approach to laparoscopic right colectomy: outcomes in 70 consecutive cases. J Am Coll Surg 2004; 199 (5): 677-9.

19. Senagore AJ, Madbouly KM, Fazio VW, Duepree HJ, Brady KM, Delaney CP. Advantages of laparoscopic colectomy in older patients. Arch Surg 2003; 138: 252-6. 